\title{
Histopathology Quiz
}

A.G. B. A. K. Jayarathna, S. M. Fernandopulle, Department of Pathology, North Colombo Teaching Hospital, Ragama, Sri Lanka

\section{Case History}

A 60-year-old woman presented to the ENT clinic with painless enlargement of the left side of the upper neck for two years. On examination, there was a swelling in the parotid area measuring $3 \times 2 \mathrm{~cm}$. The lump was firm, mobile not attached to the skin or deeper tissue. Ultrasound scan of the neck showed an enlarged left parotid gland, with multiple areas of hypo-echogenicity.

Fine Needle Aspiration Cytology (FNAC) was performed on two sites of the lump

Photomicrographs of the most representative areas of cytology smears are given below.

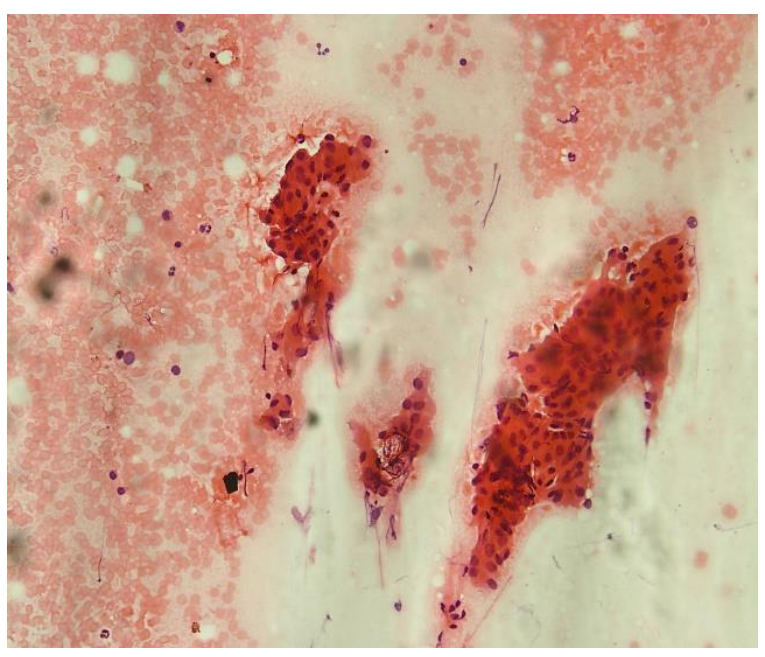

Figure 1: H\&E X100

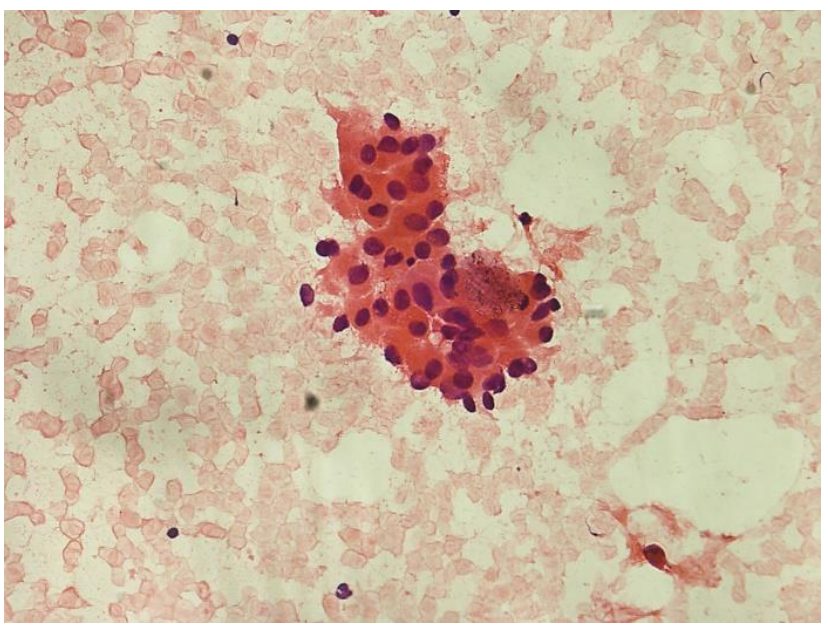

Figure 2: H\&E X200

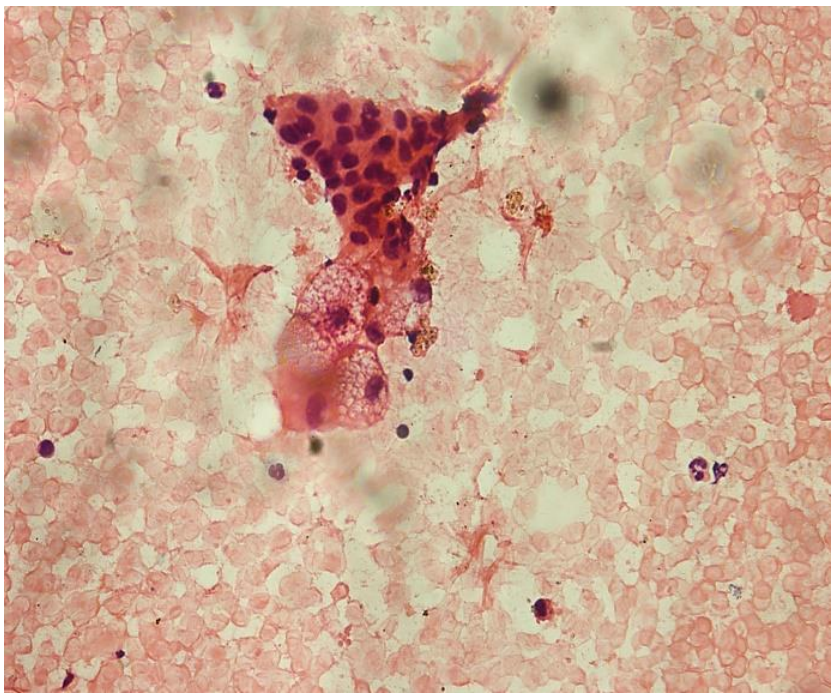

Figure 3: H\& E X200

What is your diagnosis or differential diagnoses?

See page 16-19 for answer to quiz and discussion. 